\title{
Micro-geographical variation in exposure to Schistosoma mansoni and malaria, and exacerbation of splenomegaly in Kenyan school-aged children
} Mark Booth*1, Birgitte J Vennervald ${ }^{2}$, LeeCarol Kenty ${ }^{1}$, Anthony E Butterworth ${ }^{3}$, Henry C Kariuki ${ }^{4}$, Hilda Kadzo ${ }^{5}$, Edmund Ireri 6 , Clifford Amaganga ${ }^{7}$, Gachuhi Kimani ${ }^{6}$, Joseph K Mwatha ${ }^{6}$, Amos Otedo $^{6}$, John H Ouma ${ }^{8}$, Eric Muchiri ${ }^{4}$ and David W Dunne ${ }^{1}$

Address: ${ }^{1}$ Division of Microbiology and Parasitology, Department of Pathology, University of Cambridge, Tennis Court Road, Cambridge, CB2 1QP, UK, ${ }^{2}$ Danish Bilharziasis Laboratory, Jægersborg Alle 1D, 2920 Charlottenlund, Denmark, ${ }^{3}$ Biomedical Research and Training Institute, P.O. Box CY 1753, Causeway, Harare, Zimbabwe, ${ }^{4}$ Division of Vector Borne Diseases, Ministry of Health, P.O Box 54840, Nairobi, Kenya, ${ }^{5}$ Kenyatta National Hospital, Nairobi, Kenya, ${ }^{6}$ Kenya Medical Research Institute, Nairobi, Kenya, ${ }^{7}$ Kakamega Provincial Hospital, P.O. Box 560, Kakamega, Kenya and ${ }^{8}$ Maseno University, Maseno, Kenya

Email: Mark Booth* - mb350@cam.ac.uk; Birgitte J Vennervald - bjv@bilharziasis.dk; LeeCarol Kenty - lck24@cam.ac.uk; Anthony E Butterworth - butterworth@vet.uz.ac.zw; Henry C Kariuki - schisto@wananchi.com; Hilda Kadzo - jmwatha@nairobi.mimcom.net; Edmund Ireri - jmwatha@nairobi.mimcom.net; Clifford Amaganga - jmwatha@nairobi.mimcom.net;

Gachuhi Kimani - gkimani@nairobi.mimcom.net; Joseph K Mwatha - jmwatha@nairobi.mimcom.net;

Amos Otedo - jmwatha@nairobi.mimcom.net; John H Ouma - ouma@wananchi.com; Eric Muchiri - schisto@wananchi.com;

David W Dunne - dd@mole.bio.cam.ac.uk

* Corresponding author

Published: 17 May 2004

BMC Infectious Diseases 2004, 4:13
Received: 17 November 2003

Accepted: 17 May 2004

This article is available from: http://www.biomedcentral.com/I47I-2334/4//3

(C) 2004 Booth et al; licensee BioMed Central Ltd. This is an Open Access article: verbatim copying and redistribution of this article are permitted in all media for any purpose, provided this notice is preserved along with the article's original URL.

\begin{abstract}
Background: Schistosoma mansoni and Plasmodium falciparum are common infections of school aged children in Kenya. They both cause enlargement of the spleen, but their relative contribution to the condition of splenomegaly remains unknown in areas where both infections are endemic. Here, we have investigated whether relatively high exposure to both infections has a clinically measurable effect on this condition.

Methods: 96 children aged 6-16 years living along a ten kilometre stretch and within $4 \mathrm{~km}$ south of a river that is a source of both S. mansoni and malaria infections were examined clinically for splenomegaly along the mid clavicular line (MCL) and mid axillary line (MAL). The survey was conducted outside the malaria transmission season. The consistency of the organ was recorded as soft, firm or hard. Mapping of the locations of houses and the course of the river was undertaken. Egg counts were mapped at the household level, as were $\lg G 3$ responses to Plasmodium falciparum schizont antigen (anti-Pfs $\lg \mathrm{G} 3$ ), in order to identify areas with relatively high exposure to both infections, either infection or neither infection. ANOVA was used to test for differences in egg counts, lgG3 levels and the magnitude of spleen enlargement between these areas.
\end{abstract}

Results: 4 contiguous sectors were identified, one where anti-Pfs $\lg G 3$ responses and S. mansoni egg counts were both high, one where only anti-Pfs IgG3 responses were high, one where only egg 
counts were high, and one where both anti-Pfs lgG3 responses and egg counts were low. Spleen $M A L$ and $M C L$ values were significantly higher amongst children from the sector with highest lgG3 levels and highest egg counts but similar amongst children from elsewhere. Both egg counts and anti-Pfs IgG3 responses were significantly higher in children with $M A L$ values $>=4 \mathrm{~cm}$. Hardening of spleens was associated with proximity of domicile to the river.

Conclusions: Micro-geographical variation in exposure to S. mansoni and malaria infections can be exploited to investigate the chronic impact of these two infections. These results provide firm evidence that relatively high exposure to both infections exacerbates splenomegaly even outside the malaria transmission season. Major implications include assessing the burden of infection in school age-children.

\section{Background}

Infection with multiple parasitic species is a common observation in parasitological surveys of communities in tropical and sub-tropical countries [1-3], but attempts to understand their combined health impact on affected individuals and communities have been very limited in both scope and number. An inherent problem is the lack of specificity of many signs and symptoms associated with parasitic infection, which can complicate attempts at attributing morbidity to a particular cause [4].

Hepatomegaly and splenomegaly fall into this category as common signs amongst school-aged children in Africa with multiple aetiologies. Two of the most commonly attributed causes are infections with Schistosoma mansoni and Plasmodium falciparum. It has long been suggested that the presence of one species may confound or modify the effects of the other on the liver and spleen in endemic situations [5-7], but it has also been suggested that hepatosplenomegaly in infants is likely attributable to malaria infection, whereas amongst school-aged children it is more likely attributable to S. mansoni infection [8]. This paradigm has prevailed in the absence of systematic research, and the relative contribution of the two infections in the aetiology of chronic hepatosplenomegaly of school-aged children remains essentially unknown.

Recent insights have been gained from a series of epidemiological and immunological studies in Kenya. In a crosssectional study of children, morbidity profiles were compared in two communities. After testing for the effect of several other infections, only the prevalence of malaria was higher in the worst affected community, an ecological observation that led to the suggestion that co-infection with malaria may exacerbate hepatosplenic morbidity associated with schistosome infection [9]. This hypothesis received support after retrospective assays and analysis of the blood samples from the same cohort indicated that $\mathrm{Ab}$ istotypes, in particular IgG3 to P. falciparum schizont antigen, were elevated in hepatosplenic patients compared to controls [10].
Small-area variation in exposure to malaria infection estimated from mosquito densities have been associated with variation in the prevalence of splenomegaly in children up to the age of 5 years [11]. The degree of splenomegaly has also been correlated with $S$. mansoni egg counts in school-aged children $[9,12]$. However, until now, the level of joint exposure to these infections on risk or magnitude of splenomegaly has not been investigated. Here, we have undertaken a retrospective study of splenomegaly amongst a cohort of children selected for a longitudinal study on the basis of ultrasound detectable hepatomegaly [12]. Exposure to malaria was assessed by measuring IgG3 responses to $P$ falciparum schizont antigen (anti-Pfs IgG3) whereas exposure to schistosomiasis was assessed by egg counts. These measurements were supplemented with geographical data to identify areas of low and high transmission of each infection.

\section{Methods}

The study area and cohort have been described in detail elsewhere [12]. Briefly, 96 children were enrolled in October 1999 on the basis of having ultrasound detectable hepatomegaly. The majority of these children also presented with splenomegaly. The children were living in Mbeetwani community, situated close to the River Kambu in the district of Makueni, Kenya and attending Mbeetwani school. They were examined clinically by four clinicians at baseline to record hepatomegaly below the mid sternal line (left lobe) and mid clavicular line (right lobe), and spleen enlargement below the mid axillary line (MAL) and mid clavicular line (MCL). Enlargement was measured in $\mathrm{cm}$ extension below the rib cage. Also recorded was the consistency of the organ if palpable. Organs were recorded as being either soft, firm or hard as described previously [12]. An ultrasonograpic examination of the liver was conducted by experienced ultrasonographers to identify any cases of peri-portal fibrosis.

Egg counts were estimated using the Kato-Katz technique [13] from 3 stool samples (2 readings per stool), submitted before treatment. The IgG3-response to schizont antigen was measured by ELISA, as previously described [14], 
from blood samples collected before praziquantel treatment, as well as one and two years after praziquantel treatment. Preliminary repeated-measures analysis of the IgG3 data indicated no significant difference in the responses over time ( $\mathrm{F}=0.123, p=0.884)$; however not all children contributed blood samples at all surveys. Data from the first year follow-up were available for more children than any other survey, and these data were therefore used to map the distribution of IgG3 across the study area.

\section{Analysis}

The longitude and latitude of each house were recorded using a Magellan GPS 315 receiver. Co-ordinates were recorded as degrees and decimal minutes, to 3 decimal places. Most measurements were made using signals from at least 5 satellites. The error associated with each measurement was estimated as less than 5 metres. The course of the river was determined by taking readings from the river-bed approximately every 100 metres along a ten kilometre stretch that extended beyond the borders of the study area.

Due to the proximity of the study area to the equator, the distance of each household from the river and the western edge of the study area was estimated using the Pythagorean formula for the distance between two objects along a flat surface. This calculates the distance in degrees between two points as

$d=\sqrt{ }\left(\left(\mathrm{X}_{2}-\mathrm{X}_{1}\right)^{2}+\left(\mathrm{Y}_{2}-\mathrm{Y}_{1}\right)^{2}\right.$

where $X_{1} Y_{1}$ are the decimal degree co-ordinates of one point, and $\mathrm{X}_{2}$ and $\mathrm{Y}_{2}$ are the co-ordinates of the second point. Multiplying $d$ by 111.2 , which is the distance in kilometres corresponding to one degree of either longitude or latitude at the equator, yields the distance between a pair of co-ordinates in kilometres. The shortest distance to the river for each household was estimated by comparing the distance of the house to all points taken during the mapping exercise. The western edge of the study area was taken to be the north-south transect running through the furthest point west recorded for the river.

Neigbourhood statistics were estimated in Arcview 3.2 with Splus Spatial Statistics module. Geographical coordinates of each house were first replaced with co-ordinates on a grid measuring 300 by 300 units. Egg counts and antibody OD values were averaged within houses. The average assigned to a household was assumed to be constant within a radius of 0.3 miles around each household, except where houses were closer than this distance in which case the average value of the measurement in the two houses was calculated for that position in the grid.
The study area was divided into four sectors by bisecting the east-west and north-south transects at $1.2 \mathrm{~km}$ south and $4 \mathrm{~km}$ east of the western edge of the study area. This yielded sectors of different area but similar numbers of houses in the north-west (Sector A), north-east (Sector B), south-west (Sector C) and south-east (Sector D). ANOVA with Tukey post-hoc analysis was then used to test for differences between each parameter across sectors, after converting egg counts to normal scores since the raw data were not normally distributed. Finally, differences in egg counts and IgG3 values were assessed by ANOVA between individuals above and below spleen enlargement $>=4 \mathrm{~cm}$ along the MAL. This analysis was conducted in SPSS.

\section{Results \\ Geographical distribution of households and exposure parameters}

Houses of children in the cohort were all distributed south of the River Kambu (Figure 1), which ran between its source to the west of the study and its outlet into the Athi river several kilometres beyond the eastern border of the community. The study area was approximately rectangular, covering a distance of $10 \mathrm{~km}$ from west to east and 4 kilometres north to south below the course of the river. For the purposes of analysis with sufficient power to detect small area differences in the prevalence of morbidity, the study area was divided into four contiguous sectors with approximately equal numbers of individuals in each sector. In the following description, A corresponds to the north-west sector of the study area, B represents the northeast sector, C corresponds to the south-west sector, and D represents the south-east sector.

Neighbourhood maps of $S$. mansoni egg counts and antiPfs IgG3 levels one year after treatment are illustrated in Figures 2a and 3a respectively. After partitioning the study area into the sectors described above, the pre-treatment distributions of normalised $S$. mansoni egg counts were observed to vary significantly between sectors $(\mathrm{F}=8.8, \mathrm{p}$ $=<0.001)$ as were 1-year post-treatment IgG3 OD's against schizont antigen $(\mathrm{F}=11.8 \mathrm{p}<0.001)$. These results are illustrated with box plots in Figures $2 \mathrm{~b}$ and $3 \mathrm{~b}$ respectively. ANOVA of these data with post-hoc analysis (Table 1) confirmed that egg counts were significantly higher in the two western sectors (A and $\mathrm{C}$ ), whereas IgG3 levels were significantly higher in the two northern sectors (A and $\mathrm{B}$ ). Additional analysis of IgG3 levels revealed a strong but non-linear decrease in OD value with increasing distance from the river (Figure 4).

\section{Geographical variation in the degree of splenomegaly}

In Figure 5, variation in spleen enlargement along the mid axillary line (Figure 5a) and mid clavicular line (Figure $5 b$ ) is depicted in box plots for each sector. Analysis of spleen enlargement before treatment by ANOVA revealed 


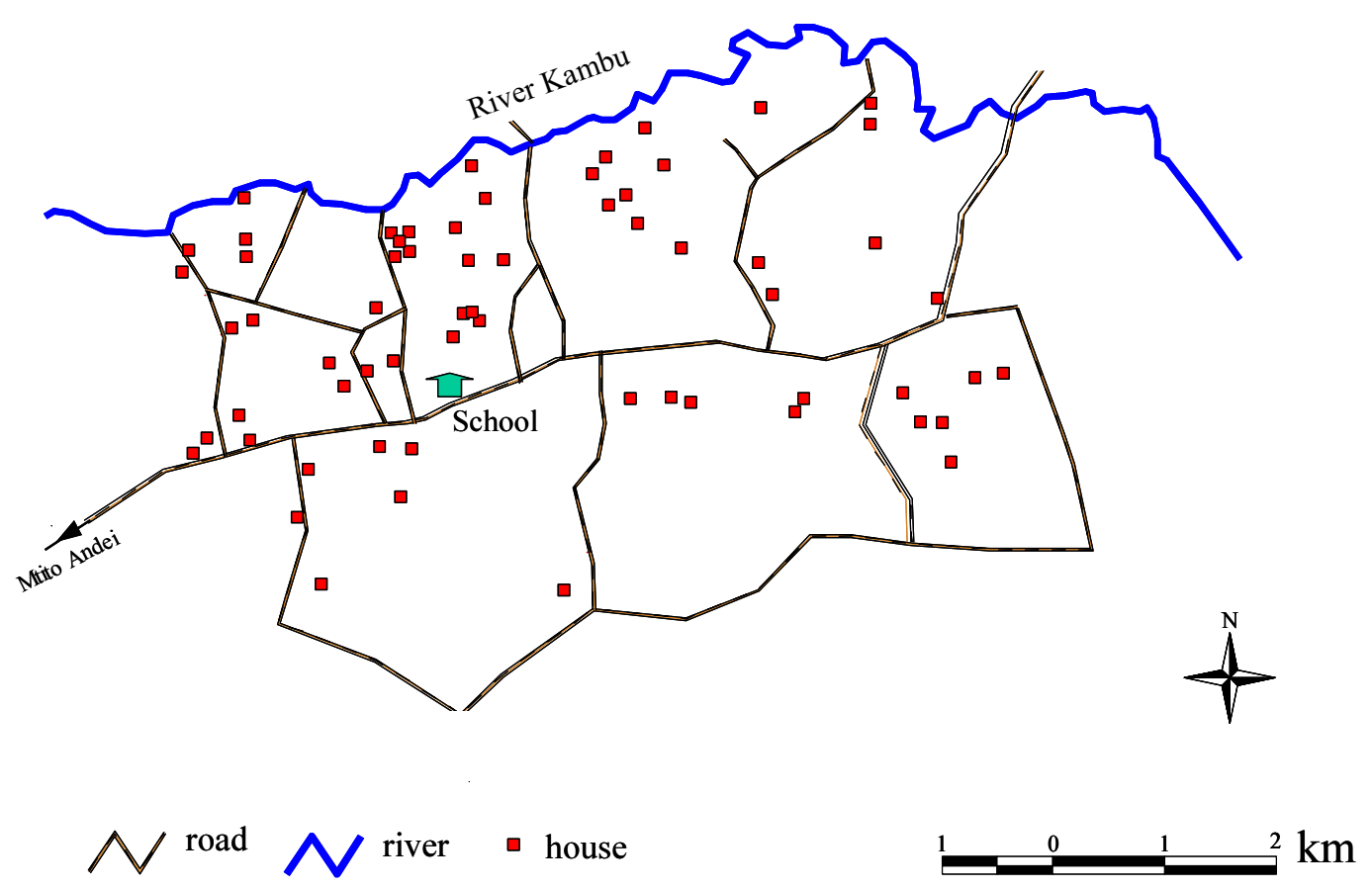

Figure I

Map of the study area showing the course of the River Kambu, positions of cohort members households and motorable roads.

a significant difference between sectors in terms of both MAL enlargement $(F=7.12, \mathrm{p}=<0.001)$ and MCL enlargement $(\mathrm{F}=7.22, \mathrm{p}<0.001)$. Post-hoc analysis of MAL enlargement indicated that children from Sector A (high IgG3, high egg counts) had significantly larger spleens than those from areas with either high IgG3 levels and low egg count (Sector A vs Sector B: $p=0.016$ ), low IgG3 and high egg counts (Sector A vs Sector C: $\mathrm{p}=0.001$ ), or low IgG3 and low egg counts (Sector A vs Sector D: p = $0.001)$. No other comparison between sectors was significant. Post-hoc analysis of MCL enlargement revealed that children from Sector A had greater enlargement than children from Sector B, but the difference was not significant (Sector A vs Sector B: $\mathrm{p}=0.081$ ). However, MCL enlargement from children from sector A was significantly greater than children from either Sector C (Sector A vs Sector C: $p$ $<0.001$ ), or Sector D (Sector A vs Sector D: $p=0.002)$. No other comparison was significant. Irrespective of sector children with spleen MAL values $>=4 \mathrm{~cm}$ had significantly higher egg counts $(\mathrm{F}=9.03, \mathrm{P}=0.003)$ and IgG3 values $(\mathrm{F}$ $=9.63, \mathrm{P}=0.003)$ than those with a lower depree of enlargement.

The probability of presenting with an enlarged and hardened spleen also varied significantly between sectors. The prevalence was $40 \%$ in Sector A ( $\mathrm{N}=28$, high IgG3 levels, low egg counts), $31 \%$ in sector $\mathrm{B}(\mathrm{N}=23$, high IgG3 levels, low egg counts), $14 \%$ in Sector $\mathrm{C}(\mathrm{N}=21$, low IgG3 levels, high egg counts) and $14 \%$ in Sector $\mathrm{D}(\mathrm{N}=24$, low IgG3 levels, low egg counts). Post-hoc analysis indicated that the two sectors closest to the river were not different in terms of prevalence of enlarged and hardened spleens, and that majority of cases of hardened and enlarged spleens (25/ 35 ) were observed to live within 1 kilometre south of the river.

\section{Geographic variation in hepatomegaly and fibrosis}

There was no observed variation across sectors in the extent of hepatomegaly as measured along the mid sternal line or mid clavicular line. No child presented with any evidence of peri-portal fibrosis.

\section{Discussion}

Local variation in the level of exposure is being increasingly recognised as an important determinant of the risk of morbidity attributable to parasitic infections. Most research efforts have previously focussed on factors affecting the micro-epidemiology of malaria [11,15-18], although it has been also observed that exposure to $S$. mansoni infection can vary over time within small areas 
a)

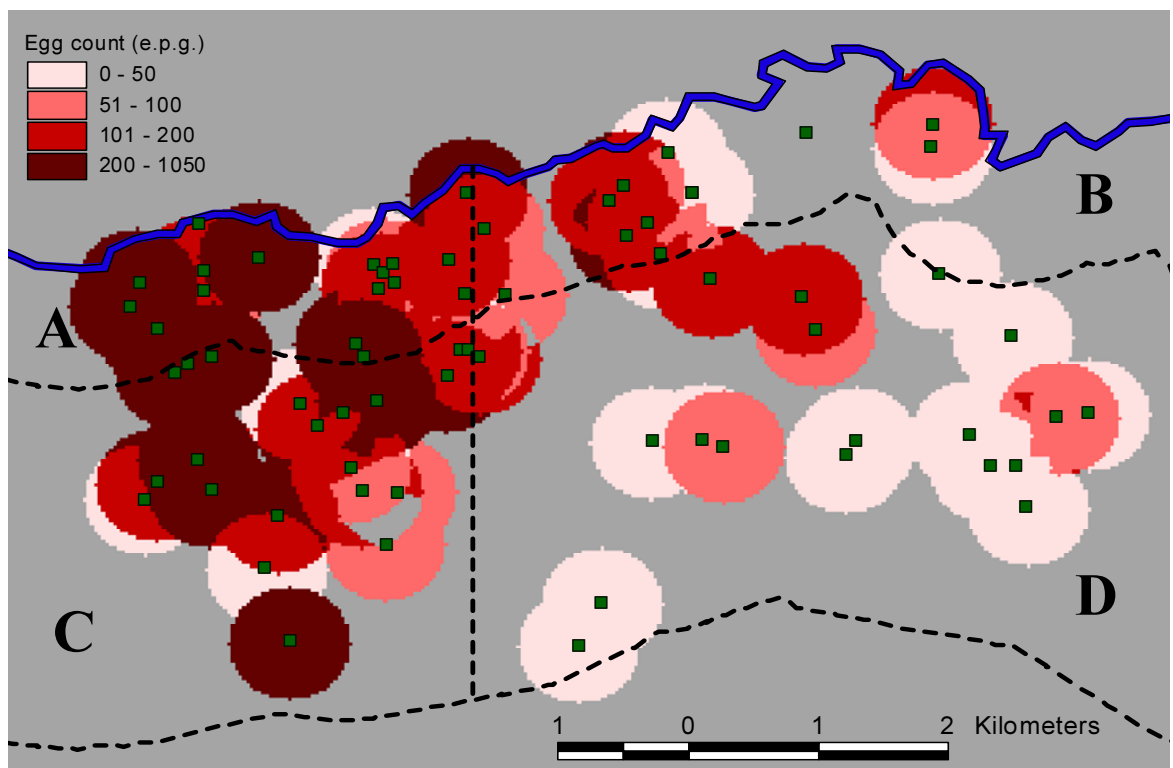

b)

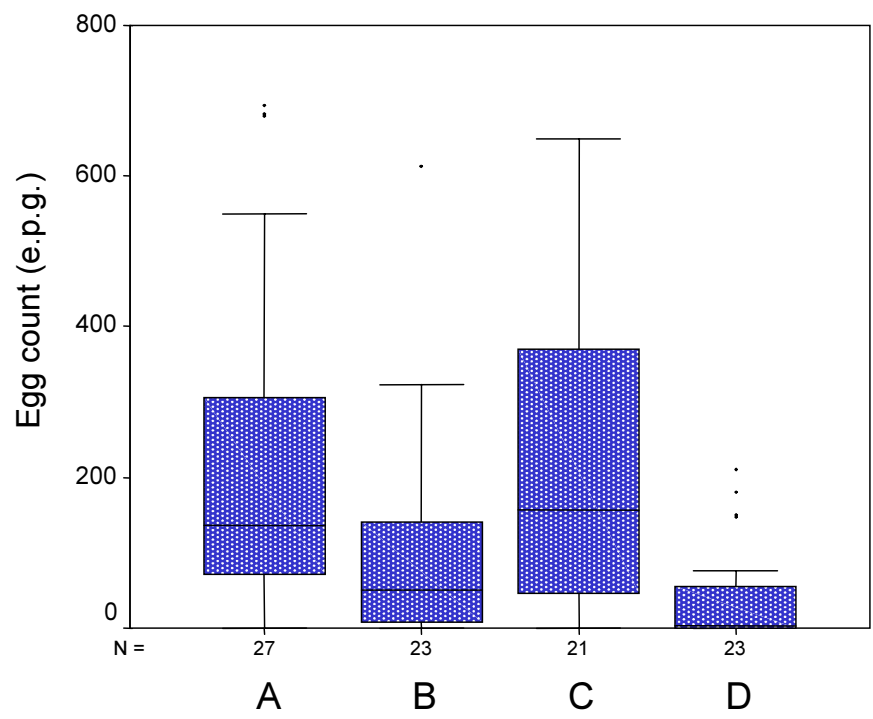

Sector

\section{Figure 2}

Neighbourhood map showing the geographical distribution of S. mansoni egg counts before treatment (Figure 2a). Also shown in Figure $2 a$ are the lines partitioning the study area into four sectors $(A, B, C$ and $D)$ as described in the text. Box and whisker plots of egg counts stratified by these sectors are shown in Figure $2 \mathrm{~b}$. The horizontal lines in each box correspond to the median values, the lower edge of the box is the $25 \%$ ile, the upper edge of the box is the $75 \%$ ile. The whiskers represent the range of data beyond these percentiles, excluding outliers. 
a)

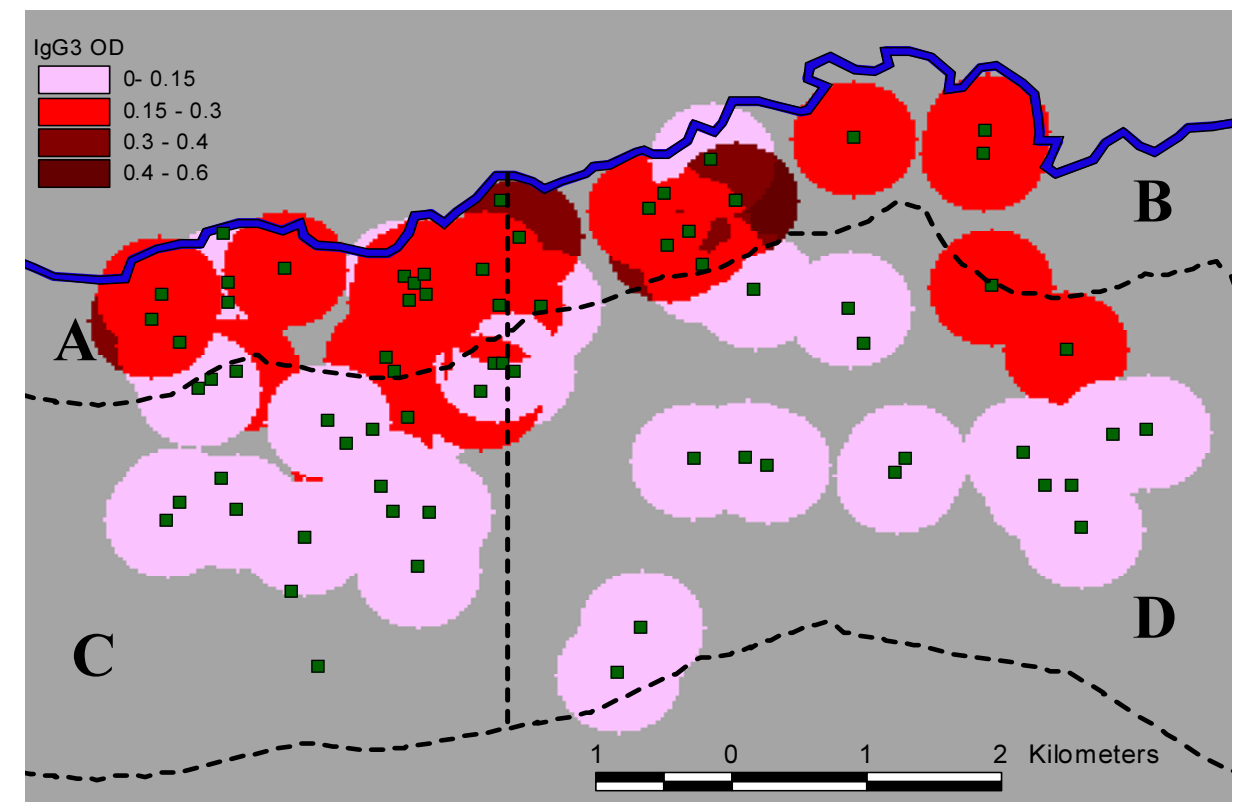

b)

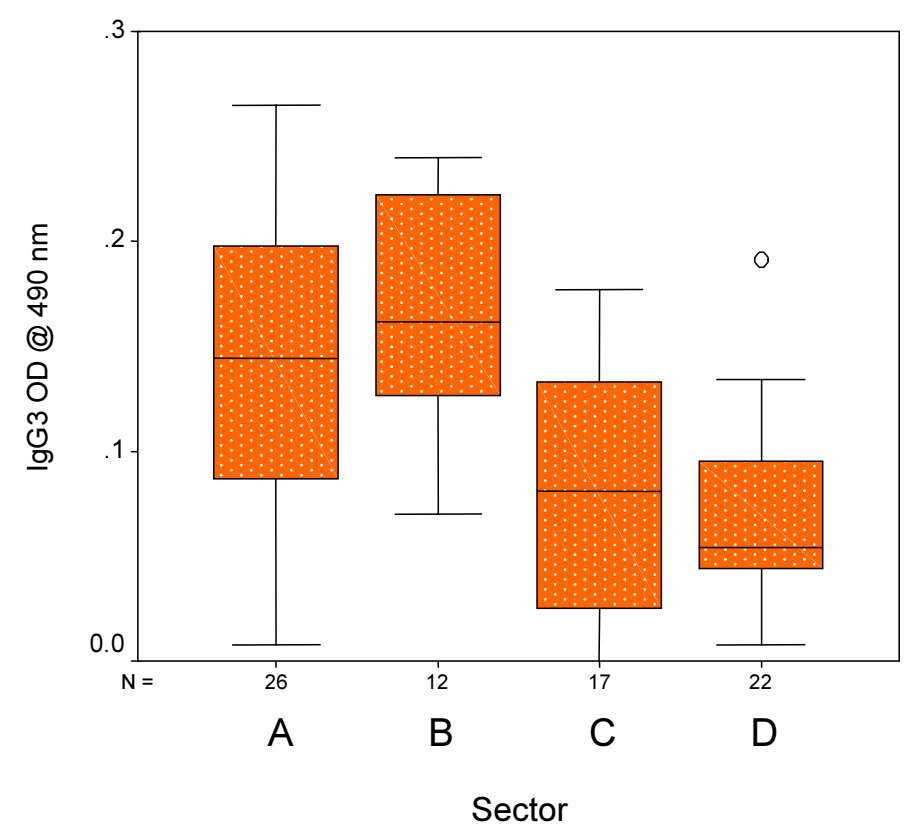

Figure 3

Neighbourhood map illustrating the geographical distribution of $\operatorname{lgG} 3$ responses (OD at $490 \mathrm{~nm}$ ) to $P$. falciparum schizont antigen I year after treatment with praziquantel (Figure 3a), together with box and whisker plots of lgG3 responses values stratified by sector (Figure $3 b$ ). 
Table I: Results of post-hoc analysis of normalised S. mansoni egg counts and untransformed IgG3 responses against schizont antigen across sectors. $m$ - mean difference between sectors (row-column) $p$ - level of significance. Cells above the diagonal correspond to comparisons of egg counts between sectors, whereas cells below the diagonal correspond to comparisons of IgG3 OD values.

\begin{tabular}{cllllllll}
\hline Sector & & A & & B & & C & D \\
\hline & $m$ & $p$ & $m$ & $p$ & $m$ & $p$ & $m$ \\
\hline A & & & 0.65 & 0.039 & 0.11 & 0.969 & 1.10 & $<0.001$ \\
B & 0.03 & 0.365 & & & -0.53 & 0.156 & 0.46 & 0.253 \\
C & -0.07 & 0.001 & -0.10 & $<0.001$ & & 0.99 & 0.001 \\
D & -0.08 & $<0.001$ & -0.11 & $<0.001$ & -0.01 & 0.979 & \\
\hline
\end{tabular}

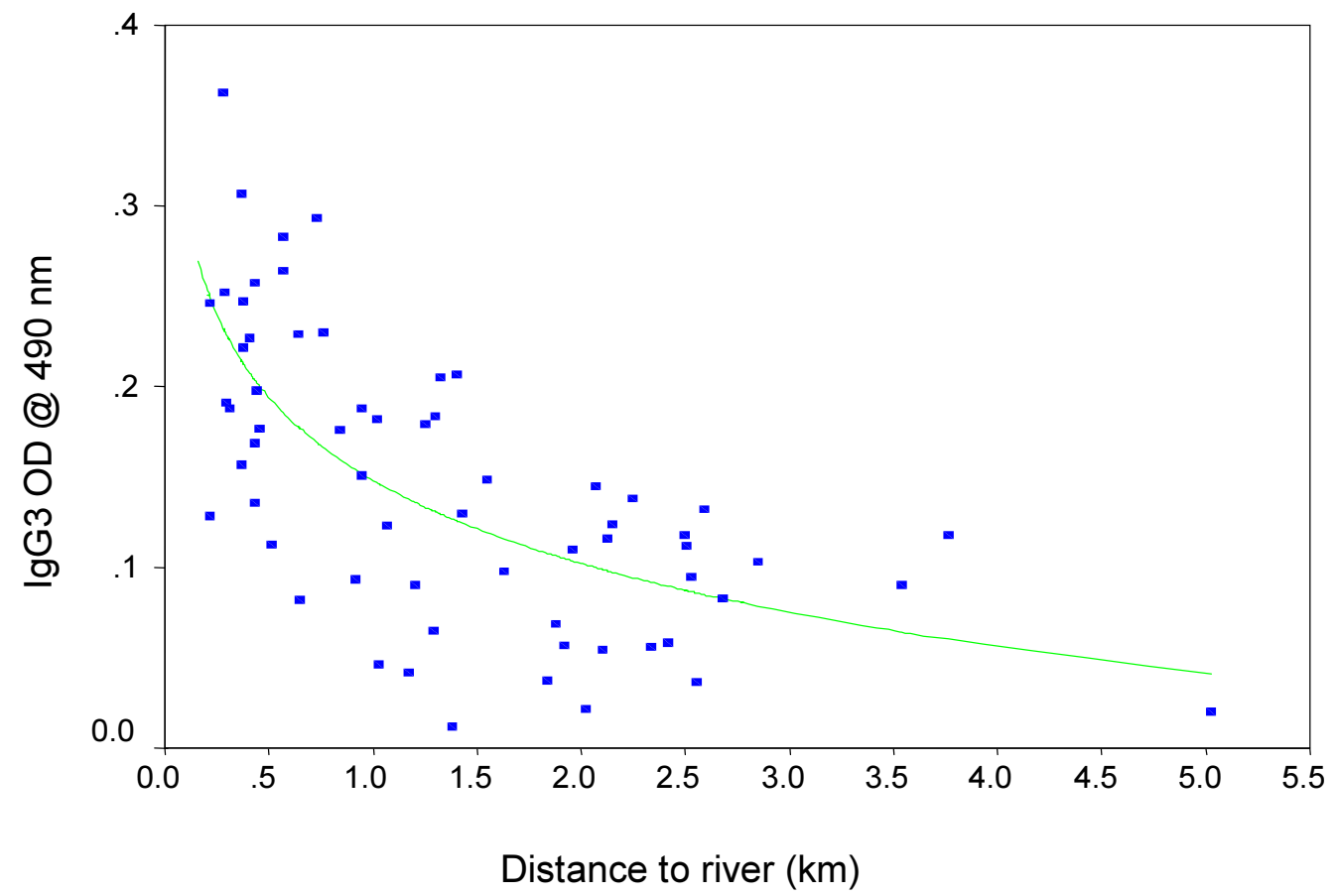

\section{Figure 4}

Scatter plot illustrating the correlation between $\lg G 3$ responses to $P$. falciparum schizont antigen, measured one year after praziquantel treatment, and distance to the river from each domicile

due to environmental variables such as distance to the transmission site $[19,20]$ and micro-climatic effects on the ecology of snail intermediate hosts [21]. Here, we have demonstrated for the first time that small area variation in exposure to both malaria and schistosomiasis can be exploited in efforts to understand their combined effects on the health of school-aged children living in areas with endemic infections.
Here, we have focused on whether or not variation in exposure to malaria and schistosome infections over a small area was correlated with variation in the degree of splenomegaly, recorded during an examination of children with ultrasound detectable hepatomegaly. The cohort was formed as part of a longitudinal study of the benefits of praziquantel treatment [12]. Although the selection process meant that the cohort was not necessarily representative of the community, the lack of geograph- 
a)

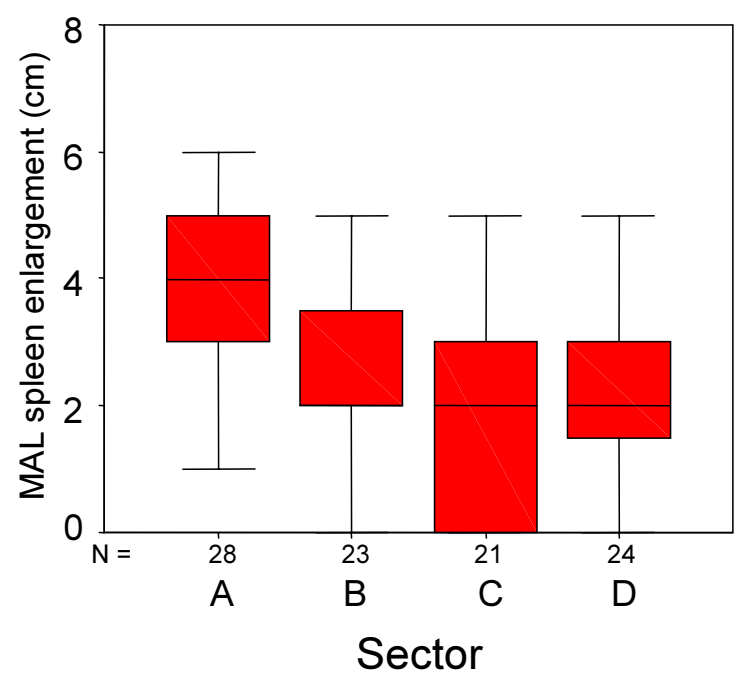

b)

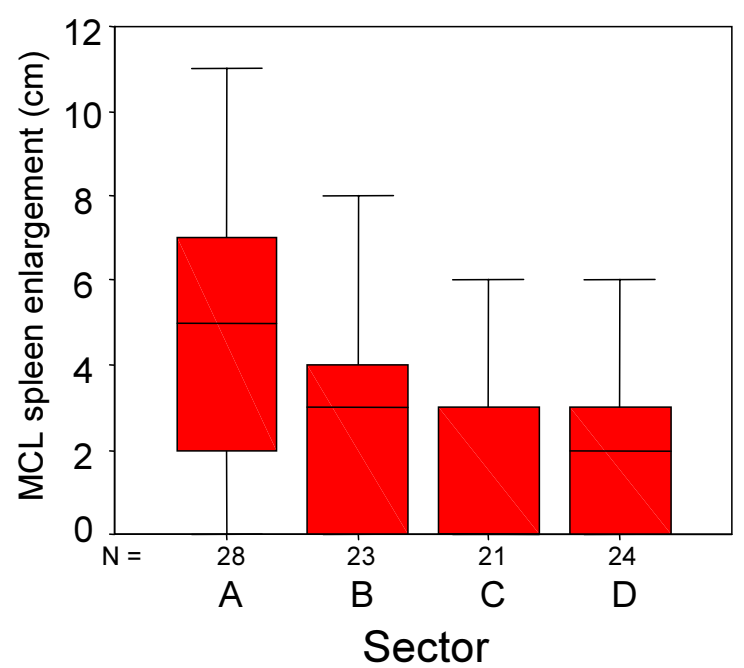

Figure 5

Box and whisker plots illustrating variation in the degree of splenomegaly along the mid axillary line (Figure 5a) and along the mid clavicular line (Figure $5 b$ ). Each plot represents data from one sector corresponding to variation in egg counts and lgG3 responses to $P$. falciparum schizont antigen. 
ical variation in hepatomegaly indicates that our observations concerning splenomegaly are not simply a proxy for hepatomegaly. The primary observation was that the extent of splenomegaly, irrespective of whether it was measured below the mid axillary line or mid clavicular line, was greatest amongst children living in a small area where both $S$. mansoni egg counts and IgG3 responses to malaria schizont antigen were significantly elevated. There was no difference in the extent of splenomegaly amongst children from elsewhere in the study area.

Together, these observations suggest that children with relatively high levels of exposure to both parasites were measurably worse affected in terms of spleen enlargement. An important question, though, is whether or not elevated IgG3 responses to $P$. falciparum schizont antigen are an appropriate proxy for exposure to malaria infection. As all examinations were conducted towards the end of the dry season, very few cohort members were expected to present with either clinical malaria or blood-smear detectable parasitaemia. We therefore required a proxy measure of exposure to malaria that was sensitive enough to reveal small area variation. In the present study, the highest IgG3 responses to schizont antigen were clustered along the northern border of the study area formed by the course of the river Kambu, and there was a rapid decline in this response with increasing distance from the river. This observation is consistent with the idea of IgG3 as a proxy measure of exposure, and this response may be expected to fulfil that role for a number of other reasons. It is a dominant IgG sub-class response to malaria antigens and toxins [22,23], but has a short half-life, and it has been hypothesised that the response wanes rapidly in areas of seasonal transmission [24]. Furthermore, IgG3 responses to blood stage antigen have been correlated with the level of exposure to infection during a bednet intervention in western Kenya [25] - a further indication that reducing exposure to malaria infection results in a measurable difference in this antibody isotype response. Finally, the distance over which the decline in IgG3 responses was measured is consistent with observations from other areas concerning the limited flight range of mosquitoes [26], and personal observations have made it clear that during the dry season there is no other surface water in the area that could harbour mosquito larvae. It is therefore reasonable to conclude that children with elevated responses had been recently exposed, or were most heavily exposed during the transmission season.

The use of egg counts as a measure of exposure to $S$. mansoni infection is less equivocal, especially amongst children. Children with the highest egg counts lived at the western end of the study area, which was concomitant with unpublished observations concerning the distribution of snails prior to the study, as well as the availability of surface water at different times of year. At the western end of the river, the surface water is less transient than at the east and there were more snails before treatment (HC. Kariuki, personal observation). Local residents situated at the western end of the river therefore are therefore likely to have experienced higher cumulative exposure than residents at the eastern end of the river, where surface water is often unavailable and wells are dug into the dry riverbed to extract subterranean water.

Hardened spleens were associated with relatively high egg count and a greater degree of splenomegaly, but the geographical clustering of hard spleens extended beyond the sector with highest IgG3 titres and high egg counts into the sector with high IgG3 levels and low egg counts. These observations alone would suggest a dominant role for malaria in the aetiology of hardened spleens, but we have recently reported elsewhere [27] that the prevalence of hard spleens reduced significantly after treatment of $S$. mansoni infection with praziquantel, and only a few children presented with hard spleens three years after treatment. Further analysis of these data will indicate whether or not the presence of hardened spleens was associated with exposure to malaria only, or attributable to exposure to both infections.

The strong negative correlation between anti-Pfs IgG3 level and distance to the river offers insights into other observations concerning this isotype. A low level of IgG3 antibodies against $P$. falciparum variant surface antigen (VSA) was recently associated with an increased risk of severe malaria in children from Gabon [28]. The authors suggested this association was due to the inability of affected individuals to produce a sustained anti-VSA response. Their hypothesis is supported by observations of genetic restriction in the production of IgG3 responses against malaria antigens $[29,30]$. However, it is equally plausible that a low IgG3 response is simply a marker for reduced exposure, and that concomitantly reduced exposure to VSAs is a risk factor for severe malaria upon infection.

\section{Conclusions}

Although the potential for malaria infections to affect the health of school-aged children in Kenya has been recently highlighted [31], our results stress the importance of considering the joint impact of multiple-species infections when addressing the health of children in this age group. This study has also demonstrated the value of a multidisciplinary approach to investigating the impact of schistosome and malaria infections. Whereas we have focused on splenomegaly in the present study, it is possible that enlargement of the spleen is not the only form of morbidity that is exacerbated by relatively high exposure to malaria and schistosomiasis. Further analysis of the 
present cohort will therefore focus on whether or not the outcome of praziquantel treatment for schistosomiasis on both hepatomegaly and splenomegaly was associated with exposure to malaria infection.

\section{Competing interests}

None declared.

\section{Authors' contributions}

$\mathrm{MB}$ conceived of, and conducted, the analysis, and drafted the manuscript. BJV and AEB performed clinical examinations and participated in the design of the study. CA and AO conducted clinical examinations. LCK conducted the lab asssays. HK and EI conducted ultrasonographic examinations of the children. CHK, GK, JM, JHO and EM participated in the planning and execution of field activities. DWD participated in the design of the study and in fieldwork.

\section{Acknowledgements}

The authors thank the children and parents of Mbeetwani for their cooperation during this project, as well as Kanyi for his help with the mapping. Financial support was obtained from Wellcome Trust and The Commission of the European Community's, Science and Technology for Development Programme (INCO-DC contract ICI8 CT97-0237 and INCO-DEV contract ICA4-CT-1999-10003).

\section{References}

I. Buck AA, Anderson RI, MacRae AA: Epidemiology of poly-parasitism. I. Occurrence, frequency and distribution of multiple infections in rural communities in Chad, Peru, Afghanistan, and Zaire. Tropenmed Parasitol 1978, 29:6I-70.

2. Booth M, Bundy DA: Estimating the number of multiple-species geohelminth infections in human communities. Parasitology 1995, III ( Pt 5):645-653.

3. Howard SC, Donnell CA, Chan MS: Methods for estimation of associations between multiple species parasite infections. Parasitology 200I, I 22:233-25I.

4. Booth M: The application of attributable risk analysis in helminth epidemiology. Parasitology Today 1998, I 4:497 -4500.

5. Nelson GS: Schistosoma mansoni infection in the West Nile District of Uganda part III. the spleen and S. mansoni infection. East African Medical Journal 1957, 35:543 -5547.

6. Ongom VL, Bradley DJ: The epidemiology and consequences of Schistosoma mansoni infection in West Nile, Uganda. I. Field studies of a community at Panyagoro. Trans $R$ Soc Trop Med Hyg 1972, 66:835-85I.

7. Buck AA, Anderson RI, MacRae AA: Epidemiology of poly-parasitism. IV. Combined effects on the state of health. Tropenmed Parasitol 1978, 29:253-268.

8. Whittle H, Gelfand M, Sampson E, Purvis A, Weber M: Enlarged livers and spleens in an area endemic for malaria and schistosomiasis. Trans $R$ Soc Trop Med Hyg 1969, 63:353-36I.

9. Fulford AJ, Mbugua GG, Ouma JH, Kariuki HC, Sturrock RF, Butterworth AE: Differences in the rate of hepatosplenomegaly due to Schistosoma mansoni infection between two areas in Machakos District, Kenya. Trans R Soc Trop Med Hyg 1991, 85:48I-488.

10. Mwatha JK, Jones FM, Mohamed G, Naus CW, Riley EM, Butterworth AE, Kimani G, Kariuki CH, Ouma JH, Koech D, Dunne DW: Associations between anti-Schistosoma mansoni and anti-Plasmodium falciparum antibody responses and hepatosplenomegaly, in Kenyan schoolchildren. J Infect Dis 2003, 187:|337-|34|.

II. Clarke SE, Bogh C, Brown RC, Walraven GE, Thomas CJ, Lindsay SW: Risk of malaria attacks in Gambian children is greater away from malaria vector breeding sites. Trans $R$ Soc Trop Med Hyg 2002, 96:499-506.

12. Vennervald BJ, Kenty LC, Butterworth AE, Kariuki CH, Kadzo H, Ireri E, Amaganga C, Gachuhi K, Mwatha JK, Otedo A, Booth M, Ouma JH, Dunne DW: Detailed clinical and ultrasound examination of children and adolescents in a Schistosoma mansoni endemic area in Kenya: hepatosplenic disease in the absence of portal fibrosis. Tropical Medicine and International Health 2004, 9:46I -4470.

13. Katz N, Chaves A, Pellegrino J: A simple device for quantitative stool thick-smear technique in schistosomiasis mansoni. Revista do Instituto de Medicina Tropical de Sao Paulo 1972, I 4:397-400.

14. Naus CW, Jones FM, Satti MZ, Joseph S, Riley EM, Kimani G, Mwatha $\mathrm{JK}$, Kariuki CH, Ouma JH, Kabatereine NB, Vennervald BJ, Dunne DW: Serological responses among individuals in areas where both schistosomiasis and malaria are endemic: cross-reactivity between Schistosoma mansoni and Plasmodium falciparum. J Infect Dis 2003, 187:1272-1282.

15. Greenwood BM: The microepidemiology of malaria and its importance to malaria control. Trans R Soc Trop Med Hyg 1989, 83 Suppl:25-29.

16. Smith T, Charlwood JD, Takken W, Tanner M, Spiegelhalter DJ: Mapping the densities of malaria vectors within a single village. Acta Trop 1995, 59: 1-18.

17. Smith T, Charlwood JD, Kitua AY, Masanja H, Mwankusye S, Alonso PL, Tanner M: Relationships of malaria morbidity with exposure to Plasmodium falciparum in young children in a highly endemic area. Am J Trop Med Hyg 1998, 59:252-257.

18. Thomas CJ, Lindsay SW: Local-scale variation in malaria infection amongst rural Gambian children estimated by satellite remote sensing. Trans $R$ Soc Trop Med Hyg 2000, 94:159-163.

19. Kloos H, Fulford AJ, Butterworth AE, Sturrock RF, Ouma JH, Kariuki HC, Thiongo FW, Dalton PR, Klumpp RK: Spatial patterns of human water contact and Schistosoma mansoni transmission and infection in four rural areas in Machakos District, Kenya. Soc Sci Med 1997, 44:949-968.

20. Klumpp RK, Webbe G: Focal, seasonal and behavioural patterns of infection and transmission of Schistosoma haematobium in a farming village at the Volta Lake, Ghana. J Trop Med Hyg 1987, 90:265-28I.

2I. Sturrock RF, Klumpp RK, Ouma JH, Butterworth AE, Fulford AJ, Kariuki HC, Thiongo FW, Koech D: Observations on the effects of different chemotherapy strategies on the transmission of Schistosoma mansoni in Machakos District, Kenya, measured by long-term snail sampling and cercariometry. Parasitology 1994, 109 ( Pt 4):443-453.

22. Boutlis CS, Fagan PK, Gowda DC, Lagog M, Mgone CS, Bockarie MJ, Anstey NM: Immunoglobulin G (IgG) responses to Plasmodium falciparum glycosylphosphatidylinositols are shortlived and predominantly of the IgG3 subclass. J Infect Dis 2003, 187:862-865.

23. John CC, Zickafoose JS, Sumba PO, King CL, Kazura JW: Antibodies to the Plasmodium falciparum antigens circumsporozoite protein, thrombospondin-related adhesive protein, and liver-stage antigen I vary by ages of subjects and by season in a highland area of Kenya. Infect Immun 2003, 71:4320-4325.

24. Ferrante A, Rzepczyk CM: Atypical IgG subclass antibody responses to Plasmodium falciparum asexual stage antigens. Parasitology Today 1997, 13:145 - | | 48.

25. Kariuki SK, ter Kuile FO, Wannemuehler K, Terlouw DJ, Kolczak MS Hawley WA, Phillips-Howard PA, Orago AS, Nahlen BL, Lal AA, Shi YP: Effects of permethrin-treated bed nets on immunity to malaria in western Kenya I. Antibody responses in pregnant women and cord blood in an area of intense malaria transmission. Am J Trop Med Hyg 2003, 68:6I-67.

26. Trape JF, Lefebvre-Zante E, Legros F, Ndiaye G, Bouganali H, Druilhe $P$, Salem G: Vector density gradients and the epidemiology of urban malaria in Dakar, Senegal. Am J Trop Med Hyg 1992, 47:18I-189.

27. Vennervald B, Booth M, Butterworth $A E$, Kariuki $\mathrm{CH}$, Kadzo H, Ireri E, Amaganga C, Gachuhi K, Kenty LC, Mwatha JK, Ouma JH, Dunne DW: Regression of hepatosplenomegaly in Kenyan schoolaged children after praziquantel treatment and in the absence of re-infection by Schistosoma mansoni. Transactions of the Royal Society of Tropical Medicine and Hygiene in press.

28. Tebo AE, Kremsner PG, Piper KP, Luty AJ: Low antibody responses to variant surface antigens of Plasmodium falci- 
parum are associated with severe malaria and increased susceptibility to malaria attacks in Gabonese children. Am J Trop Med Hyg 2002, 67:597-603.

29. Stirnadel HA, Beck HP, Alpers MP, Smith TA: Genetic analysis of IgG subclass responses against RESA and MSP2 of Plasmodium falciparum in adults in Papua New Guinea. Epidemiol Infect 2000, I 24:153-162.

30. Aucan C, Traore Y, Fumoux F, Rihet P: Familial correlation of immunoglobulin $\mathbf{G}$ subclass responses to Plasmodium falciparum antigens in Burkina Faso. Infect Immun 200I, 69:996-1001.

31. Brooker S, Guyatt H, Omumbo J, Shretta R, Drake L, Ouma J: Situation analysis of malaria in school-aged children in Kenya what can be done? Parasitol Today 2000, I6:183-186.

\section{Pre-publication history}

The pre-publication history for this paper can be accessed here:

http://www.biomedcentral.com/1471-2334/4/13/prepub
Publish with Biomed Central and every scientist can read your work free of charge

"BioMed Central will be the most significant development for disseminating the results of biomedical research in our lifetime. "

Sir Paul Nurse, Cancer Research UK

Your research papers will be:

- available free of charge to the entire biomedical community

- peer reviewed and published immediately upon acceptance

- cited in PubMed and archived on PubMed Central

- yours - you keep the copyright

Submit your manuscript here:

http://www.biomedcentral.com/info/publishing_adv.asp
BioMedcentral 